\title{
Knowledge, Perceptions and Attitudes toward Complementary and Alternative Therapies among Kuwaiti Medical and Pharmacy Students
}

\author{
A.I. Awad S. Al-Ajmi M.A. Waheedi \\ Department of Pharmacy Practice, Faculty of Pharmacy, Kuwait University, Jabriya, Kuwait
}

\section{Key Words}

Complementary and alternative therapies $\cdot$ Kuwaiti medical/pharmacy students

\begin{abstract}
Objective: To determine the knowledge, perceived effectiveness and harmfulness of complementary and alternative medicine (CAM) modalities, general attitude and the need for education in the use of CAM therapies among medical and pharmacy students. Methods: A descriptive and crosssectional study was performed using a pre-tested questionnaire on a randomly selected sample of 250 students in Faculties of Medicine and Pharmacy, Kuwait University. Descriptive and logistic regression analyses were used in data analysis. Results: The response rate was $88.4 \%$. CAM usage was reported by $122(55.2 \%)$ of students, and mostly associated with females (OR 4.4, 95\% Cl 1.7-11.3). Herbal products were the most commonly used (83, 37.6\%). Knowledge about 11 CAM modalities was generally poor, even among the respondents who claimed to know them most. The knowledge about herbal products was significantly better among 58 pharmacy students (49.2\%) than 32 medical students (31.4\%) (OR 2.0,95\% Cl 1.1-3.6). Massage, herbal products and prayer/ Qur'an reciting were perceived as being the most effective, while cauterization as the most harmful. Attitude toward
\end{abstract}

CAM was positive, with 176 (79.7\%) believing that CAM includes ideas and methods from which conventional medicine could benefit. Lack of trained professionals and lack of scientific evidence were the most perceived barriers for CAM implementation. 198 (89.6\%) admitted the importance of knowledge about CAM for them as future healthcare practitioners. Conclusion: The students acknowledged the need to be well educated about CAM to better advise their patients in the future.

Copyright $\odot 2012$ S. Karger AG, Basel

\section{Introduction}

Complementary and alternative medicine (CAM) has been defined as a 'group of diverse medical and healthcare systems, practices and products that are not presently considered to be part of conventional medicine' [1]. In the last decade, there has been a global upsurge in the use of CAM in both developed and developing countries [1-6]. The exact prevalence rate of CAM usage among the general population in Kuwait is not well known as there is no published study. However, studies from other Gulf countries have reported an increasing usage of CAM by the public in Saudi Arabia and United Arab Emirates [3$5]$. 
With the public interest in CAM at an increasing level worldwide, physicians and pharmacists seem to know little about CAM and are not confident in answering patient enquiries, because they have received limited or no formal education in CAM $[7,8]$. Patients often hesitate to disclose information about CAM usage due to the perception that physicians are not knowledgeable in this area and fearing disapproval of their alternative treatment [7]. This leads to poor doctor-patient relationship, which may give rise to situations where patients would be at risk of compromising their medical treatment through drug-herb interactions or the use of unexamined CAM therapies [9]. Faced with the increasing demand for CAM by the patients, healthcare providers have to be prepared to discuss its uses and limitations, as well as its possible adverse effects [9].

As practitioners have struggled with determining the emerging role of CAM therapies, students have recognized both the growth in and need for education related to CAM [9]. As a result of the significant increase in the use of CAM in recent years worldwide, there is also significant attention to it within medical, pharmacy and nursing schools, and a growing interest in its introduction and integration into undergraduate curriculums. Many schools in the Western countries now offer CAMrelated education $[10,11]$.

Several studies have been conducted in developed countries to determine the knowledge and attitude of medical, pharmacy and nursing students and academic staff on CAM, which have shown that students have a high level of interest in and positive attitude towards CAM [12-18]. In contrast, data from the developing countries is limited [19], where traditional medicine is widely practiced [6]. In view of the recognition that CAM in its various forms is enjoying growing popularity among the public in the Gulf region, the fact is that there is a lack of information on the attitude and perception of students and/or healthcare professionals towards CAM. This study sought to determine the use of CAM modalities, knowledge, perceived effectiveness and harmfulness, general attitude, and the perceived barriers to CAM use and the need for education among medical and pharmacy students.

\section{Subjects and Methods}

\section{Study Design and Population}

A descriptive, cross-sectional survey was conducted among medical and pharmacy students at Kuwait University. The ethical clearance for this study was obtained from the Human Ethics Committee, Health Sciences Center, Kuwait University.

\section{Study Sample}

The sample size was determined using Java Applets for Power and Sample Size [20]. It was calculated that a total sample of 186 students ( 93 from each faculty) would be required to determine a $20 \%$ difference in population between two groups (e.g. male vs. female) with an $80 \%$ power and a $5 \%$ significance level. A larger sample of 250 students (125 from each faculty, 198 females and 52 males) was selected to adjust for possible non-response, using stratified and systematic random sampling.

\section{Study Questionnaire}

The questionnaire was developed from previous studies that investigated attitude towards CAM among students in the USA $[10,17]$. The questionnaire contained both closed and open-ended questions. It was pre-tested for content, design, readability, and comprehension on 15 students, and modifications were made as necessary so that that the questionnaire was simple to answer, yet gave accurate data. The final version of the pre-tested questionnaire was composed of five sections: Section A provided information on demographic and other characteristics of the respondents (gender, age, faculty, year of study). It also included a question in relation to the use of 11 CAM modalities. Section B described the respondents' knowledge, perceived effectiveness and harmfulness of 11 CAM modalities. Students were asked to indicate their knowledge about each modality using a 4-point scale (never heard, heard of, know something about it, know a lot about it). If 'never heard of' was chosen, they were asked to skip answering the questions regarding effectiveness and harmfulness of that modality. Effectiveness was measured using a 5-point scale (very ineffective, ineffective, neither effective nor ineffective, effective, very effective). Harmfulness was measured using a 5-point scale (very harmful, harmful, neither harmful nor not harmful, not harmful, not very harmful). Section C described the respondents' general attitude towards CAM using 10 different statements on a 5-point scale (strongly disagree, disagree, neither agree nor disagree, agree and strongly agree). Section D identified the respondents' perceived barriers toward CAM implementation in Kuwait, and Section E explored the perceived need of the respondents for CAM education.

\section{Data Collection}

The selected students were contacted and given an explanation about the purpose of the research. Those who agreed to take part in the study were given the questionnaires and were asked to return them anonymously after being completed. They were assured of confidentiality and gave written consent to participate in the study.

\section{Data Analysis}

Data were entered into the Statistical Package for Social Sciences (SPSS, Version 17) and descriptive analysis was conducted. Responses are presented as percentage and 95\% confidence intervals (95\% CI). Confidence intervals were computed using EpiCalc 2000 (Brixton Health website). Simple cross-tabulations and logistic regression models were used to study the association between background variables (gender, age and faculty) and the dependent variables. Statistical significance was accepted at $p$ value of $<0.05$. 


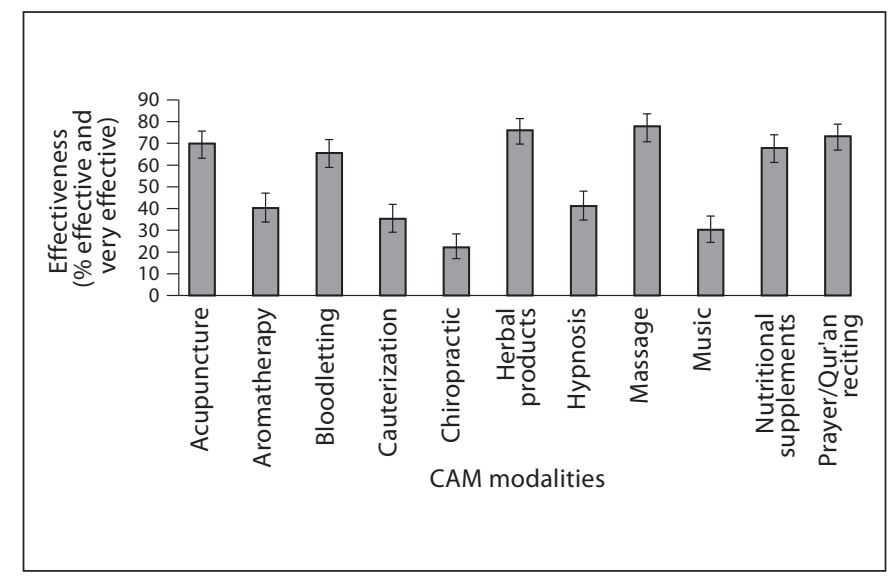

Fig. 1. Perceptions of respondents about effectiveness of CAM modalities $(n=221)$.

\section{Results}

The response rate was $88.4 \%(n=221), 29$ students declined to take part in the survey. Of the 221 students, 119 (53.8\%) and $102(46.2 \%)$ were pharmacy and medical students, respectively. The mean age was $21.8 \pm 1.7$ years (range 17-27). 122 (55.2\%) had used CAM in their life. More female students 115 (58.7\%) used CAM than male students 7 (28.0\%) (table 1). The most commonly used CAM modalities among students were: herbal products 83 (37.6\%), massage 54 (24.4\%), nutritional supplements or prayer/Qur'an reciting 51 (23.1\%), while aromatherapy 24 (10.9\%) and music 17 (7.7\%) were less commonly used CAM. The least used modalities were: acupuncture or bloodletting $3(1.4 \%)$, chiropractic or cauterization 2 $(0.9 \%)$, and hypnosis $1(0.5 \%)$.

More than one-third, 74 (33.3\%), of the study participants reported that they knew something or a lot about 4 out of 11 CAM modalities including: herbal products 90 (40.7\%), prayer/Qur'an reciting $82(37.1 \%)$, massage 80 (36.2\%), and acupuncture 76 (34.4\%). The knowledge about the other modalities was as follows: nutritional supplements $71(32.3 \%)$, bloodletting 59 (26.7\%), aromatherapy $36(16.3 \%)$, hypnosis 35 (15.9\%), cauterization or music 33 (14.9\%), and chiropractic 14 (6.4\%). The knowledge about herbal products was significantly greater among 58 pharmacy students (49.2\%) compared to 32 medical students (31.4\%) (adjusted OR 2.0, 95\% CI 1.1-3.6, p = 0.032). Females, 79 (40.9\%), were more knowledgeable in relation to prayer/Qur'an reciting than males, 3 (12.0\%) (adjusted OR 5.2, 95\% CI 1.5-11.3, $\mathrm{p}=0.01)$. Over two-thirds, 147 (66.5\%), of the respondents perceived 6 out of 11 CAM

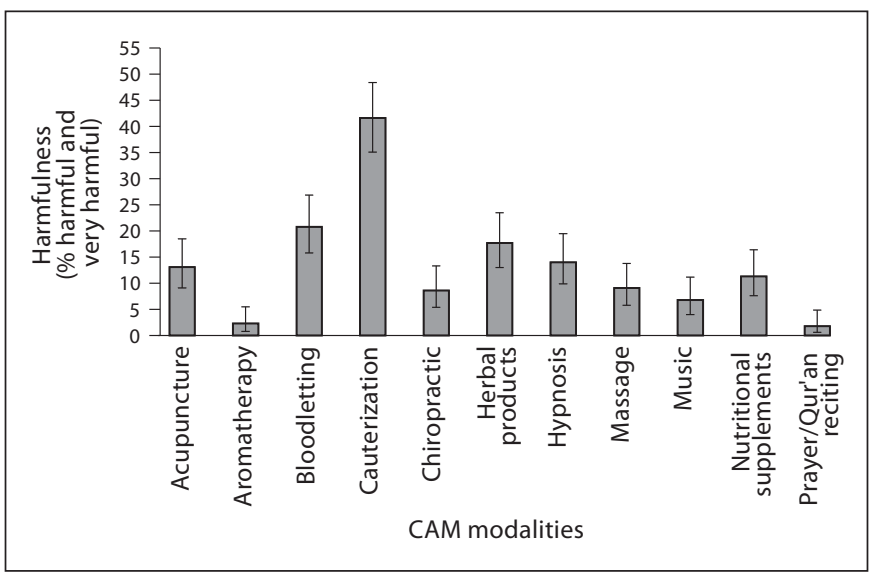

Fig. 2. Perceptions of respondents about harmfulness of CAM modalities $(\mathrm{n}=221)$.

Table 1. Background factors associated with use of CAM modalities $(\mathrm{n}=122)$

\begin{tabular}{|c|c|c|c|}
\hline \multirow[t]{2}{*}{ Factor } & \multicolumn{3}{|c|}{ Use of CAM modalities } \\
\hline & $\mathrm{n}(\%)$ & adjusted OR (95\% CI) & $\mathrm{p}$ value \\
\hline Gender & & & 0.002 \\
\hline Female & 115 (58.7) & $4.4(1.7-11.3)$ & \\
\hline Male & $7(28.0)$ & & \\
\hline Age, years & & & 0.55 \\
\hline$\leq 20$ & $24(52.2)$ & $1.2(0.45-1.5)$ & \\
\hline$>20$ & $98(58.7)$ & & \\
\hline Faculty yeara & & & 0.98 \\
\hline$\leq$ Year 3 & $54(55.1)$ & $1.1(0.48-2.7)$ & \\
\hline$\geq$ Year 4 & $68(55.3)$ & & \\
\hline Faculty & & & 0.54 \\
\hline Medicine & $56(54.9)$ & $1.2(0.66-2.2)$ & \\
\hline Pharmacy & $66(55.5)$ & & \\
\hline
\end{tabular}

${ }^{\text {a }}$ Faculty of medicine (7-year program) and faculty of pharmacy (5-year program).

modalities as effective therapies (fig. 1). Cauterization was perceived as the most harmful (fig. 2).

Regarding general attitude towards CAM, over twothirds of the respondents 'agreed' or 'strongly agreed' to the following questions: Patients should inform/consult their physicians about their use of CAM (86.0\%), CAM includes ideas and methods from which conventional medicine could benefit 176 (79.7\%), the best of CAM practices should be integrated into the conventional medicine 164 (74.2\%), and health professionals should be 
able to advise their patients about commonly used CAM methods 161 (72.8\%). Over half of the students 'disagreed' or 'strongly disagreed' that CAM treatments have no true impact on treatment of diseases (63.3\%) and that CAM is a threat to public health (61.6\%). Over $25 \%$ of respondents neither agreed nor disagreed on whether CAM therapies that have been shown to be ineffective in most evident studies should be banned (42.5\%), CAM results are placebo effect (37.1\%), CAM therapies that are not tested in a scientific manner should be discouraged (26.2\%), and that a number of CAM approaches hold promise for treatment of symptoms/diseases (25.8\%).

The anticipated barriers to the appropriate use of CAM were reported to be lack of trained professionals (79.7\%), lack of scientific evidence for practice (76.9\%), and long time for treatment (51.5\%). 198 (89.6\%) (95\% CI 84.6-93.2\%) respondents admitted that knowledge about CAM is important for them as future healthcare professionals, $80.8 \%$ of them indicated their desire for the inclusion of CAM courses in the undergraduate curriculum. The reasons for rejecting its inclusion in the curriculum included 'heavy work load/not enough time to study such courses', 'many of CAM modalities lack scientific evidence and some of them take long time to show results' and 'CAM should be included in post-graduate programs or as elective courses'.

\section{Discussion}

More than half of the students including medical students (55.2\%) reported self-use of CAM, which was close to that found among pharmacy students in Hong Kong (38.4\%) and the United Kingdom (43\%) [15, 16], but higher than that for medical students in the USA (13\%) [12]. However, the reported use was lower than for pharmacy students in Australia (78\%) [13] and medical students (over 70\%) in the USA [14]. In this study, it was not surprisingly that the most commonly used modality was herbal products, since the use of herbal remedies and prayer/Qur'an reciting are very common in the Gulf region [3-5]. The top five CAM modalities used by our study population were different from those reported by other studies. Our finding that females were more likely to use CAM confirmed studies on CAM use among the public and university students $[2,17]$, probably because as previously reported females have a more positive attitude and enthusiasm towards CAM than males [14]. However, the small sample size of the male students in this study should be taken into consideration.
Knowledge about CAM modalities differ among countries. Acupuncture, traditional Chinese medicine and herbal medicine were the best known among students in Singapore [19]. The higher knowledge claimed by the respondents regarding prayer/Qur'an reciting and herbal products might be due to the cultural background and that both modalities have been used by the general public of the Gulf countries [3-5]. Chiropractic, which is not commonly practiced in the Gulf countries, could explain the high unawareness of it among our students. Generally, the knowledge of CAM among students from Western countries was more than that displayed by our students that might be the result of CAM integration in the undergraduate curriculum in these countries $[10,11]$. The higher knowledge among pharmacy students about herbal products might be due to some courses that contain information relevant to herbal products. Higher knowledge of females about prayer/Qur'an reciting compared to males could be due its more common use among females.

The current findings showed that most of the CAM modalities, which were known by the respondents, were also perceived as effective, and this is consistent with a previous study [18]. Cauterization was perceived as the most harmful CAM modality. It is included in this study despite the fact that it had not been in any of the previous studies because it is used by the public in the Arab world $[4,5]$. This finding indicates the good awareness of our students about the harmful physical, psychological and health consequences of cauterization.

The findings of the study that about three-quarters of respondents displayed positive attitude that 'CAM includes ideas and methods from which conventional medicine could benefit', the best of CAM practices should be integrated with the conventional medicine' and 'health professionals should be able to advise their patients about commonly used CAM methods' confirmed previous findings $[12,19]$. This result could imply that our students as future practitioners believe that CAM has an important role in health care. Twenty-five percent of respondents were neutral (neither agreed nor disagreed) on statements of whether CAM therapies that have been shown to be ineffective in most evident studies should be banned, CAM results are placebo effect, and that a number of CAM approaches hold promise for treatment of symptoms/diseases. These high levels of neutrality could indicate an opportunity to augment the current undergraduate curriculum with knowledge-based elements of CAM modalities. 
In the present study, the most perceived barriers to using CAM were lack of training and lack of scientific evidence. Therefore, evidence-based training is required in the use of CAM and also the integration of CAM education in the existing curriculum to enable the future practitioners to provide better patient management.

The majority of students indicated that knowledge about CAM is important to them as future healthcare professionals, and the need for the incorporation of CAM education in the undergraduate curriculum as has been done in Western countries. These findings are consistent to those of previous studies $[12,19]$, and encouraging that most of our students realize this lack of knowledge and are eager to rectify it. This should serve as a stimulus to include CAM education in the undergraduate curriculum. Medical and pharmacy schools in the West are increasingly introducing CAM education in the curriculum, and this results in a curriculum that could provide additional knowledge of healthcare beyond the medical mainstream $[10,11]$.

The limitations of this study include extent of truthful answers and verification of respondents' claims. The odds ratio calculated for the knowledge was actually based on the students' self-assessment (knew something or a lot) since no objective measure of knowledge was used in this study.

\section{Conclusion}

Over half of the students reported self-use of 11 CAM modalities and the attitude towards CAM were positive. Knowledge of the CAM modalities was generally poor. The students acknowledge the need to be well educated about CAM to better advise their patients in the future.

\section{References}

1 Barnes PM, Bloom B, Nahin RL: Complementary and alternative medicine use among adults and children: United States, 2007. Natl Health Stat Report 2008;12:1-23.

2 Ness J, Cirillo DJ, Weir DR, Nisly NL, Wallace RB: Use of complementary and alternative medicine in older Americans: results from the Health and Retirement Study. Gerontologist 2005;45:516-524.

-3 Al Braik FA, Rutter PM, Brown D: A crosssectional survey of herbal remedy taking by United Arab Emirate (UAE) citizens in Abu Dhabi. Pharmacoepidemiol Drug Saf 2008; 17:725-732.

-4 Al-Faris EA, Al-Rowais N, Mohamed AG, Al-Rukban MO, Al-Kurdi A, Balla Al-Noor MA, Al-Harby S, Sheikh A: Prevalence and pattern of alternative medicine use: the results of a household survey. Ann Saudi Med 2008:28:4-10.

5 Al-Rowais N, Al-Faris E, Mohammad AG, Al-Rukban M, Abdulghani HM: Traditional healers in Riyadh region: reasons and health problems for seeking their advice. A household survey. J Altern Complement Med 2010; 16:199-204.

6 World Health Organization: WHO Traditional Medicine Strategy 2002-2005. Available at http://whqlibdoc.who.int/hq/2002/ who_edm_trm_2002.1.pdf (accessed 7 July 2010).
7 Zollman C, Vickers A: What is complementary medicine? BMJ 1999;319:693-696.

-8 Astin JA, Soeken K, Sierpina VS, Clarridge BR: Barriers to the integration of psychosocial factors in medicine: results of a national survey of physicians. J Am Board Fam Med 2006;19:557-565.

-9 Kreitzer MJ, Mitten D, Harris I, Shandeling J: Attitudes toward CAM among medical, nursing, and pharmacy faculty and students: a comparative analysis. Altern Ther Health Med 2002;8:44-47, 50-53.

10 Tsuruoka K, Tsuruoka Y, Kajii E: Complementary medicine education in Japanese medical schools: a survey. Complement Ther Med 2001;9:28-33.

11 ACPE Board of Directors: Draft revision of ACPE standards 2000 and proposed guidelines. 2005. Available at http://www.acpeaccredit.org/pdf/ACPEDraftRevisedStandardsandGuidelinesJune2005final.pdf (accessed 7 July 2010).

12 Greiner KA, Murray JL, Kallail KJ: Medical student interest in alternative medicine. J Altern Complement Med 2000;6:231-234.

13 Wilkinson JM, Simpson MD: Complementary therapy use by nursing, pharmacy and biomedical science students. Nurs Health Sci 2001;3:19-27.
14 Lie D, Boker J: Development and validation of the CAM Health Belief Questionnaire $(\mathrm{CHBQ})$ and $\mathrm{CAM}$ use and attitudes amongst medical students. BMC Med Educ 2004;4:2.

15 Hon EK, Lee K, Tse HM, Lam LN, Tam KC, Chu KM, Lee V, Lau C, Leung TF: A survey of attitudes to traditional Chinese medicine in Hong Kong pharmacy students. Complement Ther Med 2004;12:51-56.

16 Freymann H, Renniel T, Bates I, Nebel S, Heinrich M: Knowledge and use of complementary and alternative medicine among British undergraduate pharmacy students. Pharm World Sci 2006;28:13-18.

17 Feldman R, Laura R: The use of complementary and alternative medicine practices among Australian university students. Complement Health Pract Rev 2004;9:173-179.

18 Hopper I, Cohen M: Complementary therapies and the medical profession: a study of medical students' attitudes. Altern Ther Health Med 1998;4:68-73.

19 Yeo AS, Yeo JC, Yeo C, Lee CH, Lim LF, Lee TL: Perceptions of complementary and alternative medicine amongst medical students in Singapore - a survey. Acupunct Med 2005; 23:19-26.

20 Lenth, RV: Java Applets for Power and Sample Size (computer software) 2008. Available at http://www.stat.uiowa.edu/ rlenth/Power (accessed 5 March 2008). 